\title{
Responsiveness to change due to supportive-expressive group therapy, improvement in mood and disease progression in women with metastatic breast cancer
}

\author{
Julie Lemieux · Dorcas E. Beaton · Sheilah Hogg-Johnson · Louise J. Bordeleau • \\ Jon Hunter · Pamela J. Goodwin
}

Published online: 18 August 2007

(C) Springer Science+Business Media B.V. 2007

Erratum to: Qual Life Res (2007) 16:1007-1017

DOI 10.1007/s11136-007-9208-2

There was a typing error in the title of the original article.

The online version of the original article can be found under doi: $10.1007 / \mathrm{s} 11136-007-9208-2$.

\section{J. Lemieux}

Département d'hématologie, Unité de recherche en santé des populations, Centre hospitalier affilié universitaire de Québec, pavillon St-Sacrement, Quebec, Canada

\section{J. Lemieux}

Département de Médicine de l’Université Laval, Quebec,

Canada

J. Lemieux

Samuel Lunenfeld Research Institute of the Mount Sinai

Hospital, Toronto, Canada

J. Lemieux ( $\square)$

Unité de recherche en santé des populations, Centre de Recherche, Hôpital St-Sacrement, du Centre Hospitalier affilié de 1'Université Laval, 1050 Chemin Ste-Foy, Room JS1-01, Quebec, QC, Canada G1S 4L8

e-mail: julie.lemieux@uresp.ulaval.ca

\section{E. Beaton}

Mobility Program, Clinical Research Unit, St Michael's

Hospital, Toronto, Canada

\author{
S. Hogg-Johnson \\ Institute for Work and Health, Toronto, Canada \\ L. J. Bordeleau \\ Department of Medicine, Mount Sinai Hospital, \\ Toronto, Canada \\ J. Hunter \\ Department of Psychiatry, Mount Sinai Hospital, \\ Toronto, Canada

\section{P. J. Goodwin} \\ Department of Medicine, Samuel Lunenfeld \\ Research Institute of the Mount Sinai Hospital, \\ Toronto, Canada \\ D. E. Beaton · S. Hogg-Johnson - L. J. Bordeleau • \\ J. Hunter · P. J. Goodwin \\ University of Toronto, \\ Toronto, Canada
}

